\title{
Properties and catalytic performance of sulphate-vanadia impregnated fumed silica as oxidative catalyst
}

\author{
Nor Masdiana Zulkeple ${ }^{\mathrm{a}}$, Norhasyimah Mohd Kamal ${ }^{\mathrm{a}}$, Jamilah Mohd Ekhsan ${ }^{\mathrm{a}}$, Salasiah Che Me ${ }^{\mathrm{a}}$, Swee Ean Limª, Siew Ling Lee ${ }^{\mathrm{b}, *}$ \\ ${ }^{a}$ Chemistry Department, Universiti Teknologi Malaysia, Johor Bahru, Malaysia \\ ${ }^{b}$ Centre for Sustainable Nanomaterials, Ibnu Sina Institute for Scientific and Industrial Research, Universiti Teknologi Malaysia, 81310 UTM Skudai, \\ Johor, Malaysia \\ *Corresponding Author: sllee@ibnusina.utm.my
}

\section{Article history: \\ Received 20 Oct 2014 \\ Accepted 13 May 2015}

\section{GRAPHICAL ABSTRACT}

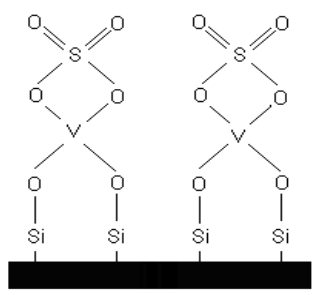

\begin{abstract}
A series of sulphate-vanadia impregnated fumed silica oxidative catalysts were synthesized via impregnation method. The samples were prepared by impregnating $1 \mathrm{wt} \%$ of vanadium and $0.2 \mathrm{M}$ of sulphuric acid onto fumed silica support. Surface area of all the silica supported samples was approximately $118 \mathrm{~m}^{2} / \mathrm{g}$. UV-Vis DRS results showed the existence of supported V species and charge transfer bands associated with $\mathrm{O}^{2-}$ to $\mathrm{V}^{5+}$ in tetrahedral environments. Catalytic performance was evaluated via epoxidation of 1-octene to 1,2-epoxyoctane using hydrogen peroxide as oxidant. It had been demonstrated that sulphate-vanadia impregnated fumed silica had high catalytic activity where 626 $\pm 0.2 \mathrm{mmol}$ epoxide was produced after $24 \mathrm{~h}$ reaction. The results implied that more oxidative sites were generated after the impregnation of $\mathrm{V}$ and sulphate onto the $\mathrm{SiO}_{2}$ matrixes.
\end{abstract}

Keywords: Oxidative catalyst, Vanadia, Sulphate, Fume silica

(C) 2015 Penerbit UTM Press. All rights reserved http://dx.doi.org/10.11113/ mjfas.v11n2.372

\section{INTRODUCTION}

Epoxides are valuable and versatile commercial intermediates. They are highly reactivity due to the highly opening strained three-membered ring [1]. Apparently, the epoxides turn out to be very important chemical products for synthesis of other materials in the fine chemical industry. Therefore, many works have been done to enhance the epoxide selectivity because of the importance of epoxides in the synthesis of organic and pharmaceutical materials.

Titania and $\mathrm{TiO}_{2}$-based materials have been reported as the most effective oxidation catalysts for various reactions, including olefin epoxidation [2,3]. Amongst, titanium-containing silicalite, TS-1 was an excellent oxidative catalyst due to presence of tetrahedrally coordinated titanium in a silicate structure [4].

Recently, an oxidative-acidic bifunctional catalyst was synthesized by impregnation of $1 \mathrm{wt} \%$ vanadium onto silica-titania aerogel [5]. It was reported that both titania and vanadium responsible in the formation of oxidative sites on the surface of the catalyst. However, the competition between titania and vanadium as oxidative catalyst could have reduced the catalytic efficiency of the material, hence making their roles unclear.

In this work, a titania free oxidative catalyst of sulphate-vanadia supported on silica was prepared. The role of the vanadium as oxidative site was reexamined. Besides, effectiveness of fumed silica, a relatively cheap silica material as catalyst support was investigated.

\section{EXPERIMENTS}

\section{$2.1 \quad$ Synthesis of catalyst}

Synthesis of sulphate-vanadia loaded onto fumed silica (Merck) was prepared via wet impregnation method at room temperature. Vanadia (1 wt \%) was dissolved in 25 $\mathrm{mL}$ of distilled water and impregnated with $2.0 \mathrm{~g}$ of $\mathrm{SiO}_{2}$. The mixture was stirred for $1 \mathrm{~h}$, dried overnight at $373 \mathrm{~K}$ and finally calcined at $823 \mathrm{~K}$ for $7 \mathrm{~h}$. Subsequently, the catalysts were further modified with $0.2 \mathrm{M}$ sulphuric acid via wet impregnation method. The final resulted material was labeled as $\mathrm{HS} / \mathrm{V} / \mathrm{SiO}_{2}$.

For comparison purpose, materials were also prepared via different synthesis methods and loading sequences in order to create dissimilar interaction among the elements in the materials. A mixture of $2.0 \mathrm{~g} \mathrm{SiO}_{2}$ and $25 \mathrm{~mL}$ of $0.2 \mathrm{M}$ sulphuric acid was stirred vigorously at room temperature for $1 \mathrm{~h}$. Later, the mixture was dried at $373 \mathrm{~K}$ for overnight and followed by calcinations at $823 \mathrm{~K}$ for $7 \mathrm{~h}$. Subsequently, 1 wt $\% \mathrm{~V}_{2} \mathrm{O}_{5}$ was loaded onto $\mathrm{SiO}_{2}$ via wet impregnation method. The loading process used 
was similar to that of synthesis procedure of $\mathrm{HS} / \mathrm{V} / \mathrm{SiO}_{2}$. The resulted material was labeled as $\mathrm{V} / \mathrm{HS}-\mathrm{SiO}_{2}$.

On the other hand, $1 \mathrm{wt} \%$ of $\mathrm{V}$ was dissolved with $25 \mathrm{~mL}$ of $0.2 \mathrm{M}$ sulphuric acid. The solution was impregnated to the $2.0 \mathrm{~g}$ of $\mathrm{SiO}_{2}$. The process was continued with dried at $373 \mathrm{~K}$ for overnight and followed by calcinations at $823 \mathrm{~K}$ for $7 \mathrm{~h}$. The resulted material was denoted as $\mathrm{V}-\mathrm{HS} / \mathrm{SiO}_{2}$.

\subsection{Characterization}

The crystallinity and phase purity of the samples were identified by $\mathrm{X}$ - ray diffraction (XRD), using a Bruker Advance D8 using Siemens 5000 diffractometer with the $\mathrm{Cu} \mathrm{K} \alpha(\lambda=1.5405 \AA)$ radiation as the diffracted monochromatic beam at $40 \mathrm{kV}$ and $40 \mathrm{~mA}$. The spectra was scanned in the $2 \theta$ range between $2^{\circ}$ and $30^{\circ}$ at a step $0.050^{\circ}$ and step time $1 \mathrm{~s}$. Diffused reflectance UV spectra were under ambient condition using a Perkin Elmer Lambda 900 DRUV/VIS spectrometer over range from 190 to $800 \mathrm{~nm}$. The surface area was determined by means of BET $\mathrm{N}_{2}$ adsorption using Quantachrom surface are analyzer. The analyzer was calibrated using $\mathrm{Al}_{2} \mathrm{O}_{3}$ as the standard material prior to analysis. On the other hand, infrared measurements were performed on a Perkin Elmer Spectrum One FT-IR spectrometer, with a spectral resolution of $2 \mathrm{~cm}^{-1}$, scan time of $10 \mathrm{~s}$ using the $\mathrm{KBr}$ pellet technique. The framework spectra were recorded in the region of $400-4000 \mathrm{~cm}^{-1}$.

\subsection{Catalytic testing}

The catalytic testing of the samples was evaluated through the epoxidation of 1-octene using aqueous $\mathrm{H}_{2} \mathrm{O}_{2}$ as oxidant. The reaction mixture containing of $8 \mathrm{mmol}$ of 1 octene (Fluka, 97\%), 8 mmol of $\mathrm{H}_{2} \mathrm{O}_{2}$ in $\mathrm{H}_{2} \mathrm{O}$ (Qrec, 30\%) in $10 \mathrm{~mL}$ acetonitrile (J.T beaker) as solvent and $70 \mu \mathrm{L}$ of cyclohexane (Fluka, 99\%) as the internal standard was placed in a round bottom flask equipped with magnetic stirrer and condenser. About $0.05 \mathrm{~g}$ catalyst was added into the solution. The reaction was carried out in oil bath at 343 $\mathrm{K}$ for $24 \mathrm{~h}$ under stirring condition. The products of the reaction were analyzed on a HP Agilent $6890 \mathrm{~N}$ gas chromatograph using Ultra-1 column.

\section{RESULTS AND DISCUSSION}

\subsection{Physical Appearance}

All the samples were light and fluffy powder. The colour of all sulphate-vanadia doped samples changed from blue to green colour after calcination at $823 \mathrm{~K}$ for $7 \mathrm{~h}$. It was suggested that, during this step $\mathrm{V}$ in these samples has changed from $\mathrm{V}(\mathrm{IV})$ toward a higher oxidation state of $\mathrm{V}(\mathrm{V})$. Similar observation was reported previously [5].

\subsection{Characterizations}

Fig. 1 shows the X-ray diffractograms of the prepared samples. The amorphous structure of $\mathrm{SiO}_{2}$ remained after impregnation and calcinations processes as indicated by the broad and featureless X-ray diffractograms. The absence of peaks in the diffractograms further suggested that no diffraction lines for sulphate or vanadia. The results may imply that both sulphate and vanadia are highly dispersed on the surface of $\mathrm{SiO}_{2}$. Alternatively, the broad and featureless X-ray diffractograms could be attributed to the low content of vanadia in the samples.

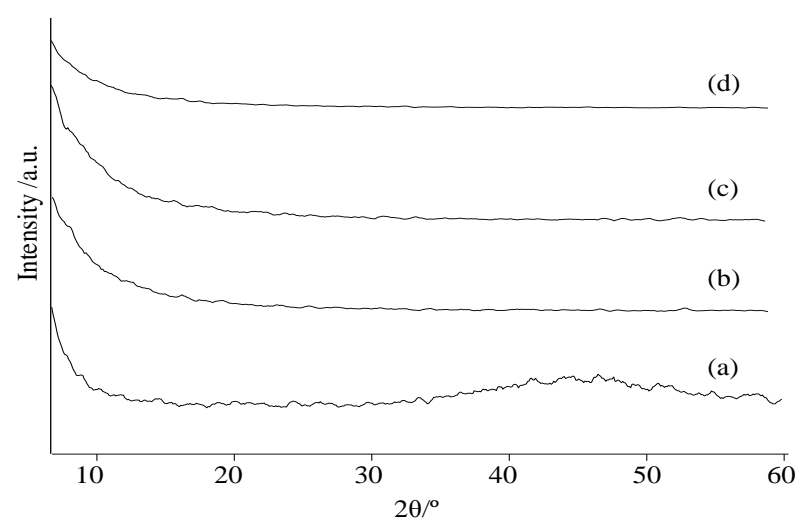

Figure.1 X-ray diffractograms of (a) $\mathrm{SiO}_{2}$, (b) $\mathrm{V} / \mathrm{HS}-\mathrm{SiO}_{2}$, (c) $\mathrm{HS} / \mathrm{V} / \mathrm{SiO}_{2}$ and (d) $\mathrm{V}-\mathrm{HS} / \mathrm{SiO}_{2}$

Table 1 shows that all the samples are having surface area in range $118-150 \mathrm{~m}^{2} / \mathrm{g}$. The high surface area fume $\mathrm{SiO}_{2}\left(150 \mathrm{~m}^{2} / \mathrm{g}\right)$ was used as catalyst support. As observed, a significant decrease of $\sim 21 \%$ in surface area was observed after impregnation of $\mathrm{V}$ and $\mathrm{H}_{2} \mathrm{SO}_{4}$ onto $\mathrm{SiO}_{2}$. The usage of $\mathrm{SO}_{4}{ }^{2-}$ group would have led to coalescence process during calcinations, bringing to partial destruction of the $\mathrm{SiO}_{2}$ structure [6,7].

Table.1 Surface area and pore volume of the samples

\begin{tabular}{lc}
\hline Samples & Surface area $\left(\mathrm{m}^{2} / \mathrm{g}\right) \pm 5 \%$ \\
\hline $\mathrm{SiO}_{2}$ & 150 \\
$\mathrm{~V} / \mathrm{HS}-\mathrm{SiO}_{2}$ & 118 \\
$\mathrm{HS} / \mathrm{V} / \mathrm{SiO}_{2}$ & 118 \\
$\mathrm{~V}-\mathrm{HS} / \mathrm{SiO}_{2}$ & 119 \\
\hline
\end{tabular}

UV-Vis DRS spectra of all the samples are depicted in Fig. 2. Generally, two bands at around $250 \mathrm{~nm}$ and $380 \mathrm{~nm}$ were detected in the samples. Absorption band in range $250-300 \mathrm{~nm}$ is attributed to the charge transfer transitions between tetrahedral oxygen ligands and the framework-substituted $\mathrm{V}^{5+}$ ions, while the band at 350-400 $\mathrm{nm}$ corresponds to $\mathrm{V}$ species on the wall surfaces [7] due to the charge transfer (CT) bands associated with $\mathrm{O}^{2-}$ to $\mathrm{V}^{5+}$ in tetrahedral (Td) environments. As can be seen in Fig. 2, sample $\mathrm{HS} / \mathrm{V} / \mathrm{SiO}_{2}$ exhibited a more intense band at 250 $\mathrm{nm}$ and $380 \mathrm{~nm}$ compared to other samples, implying this sample may consist of more $\mathrm{V}^{5+}$ species. However, the synthesis methods did not give significant impact on the type of $\mathrm{V}$ species generated in the samples. 


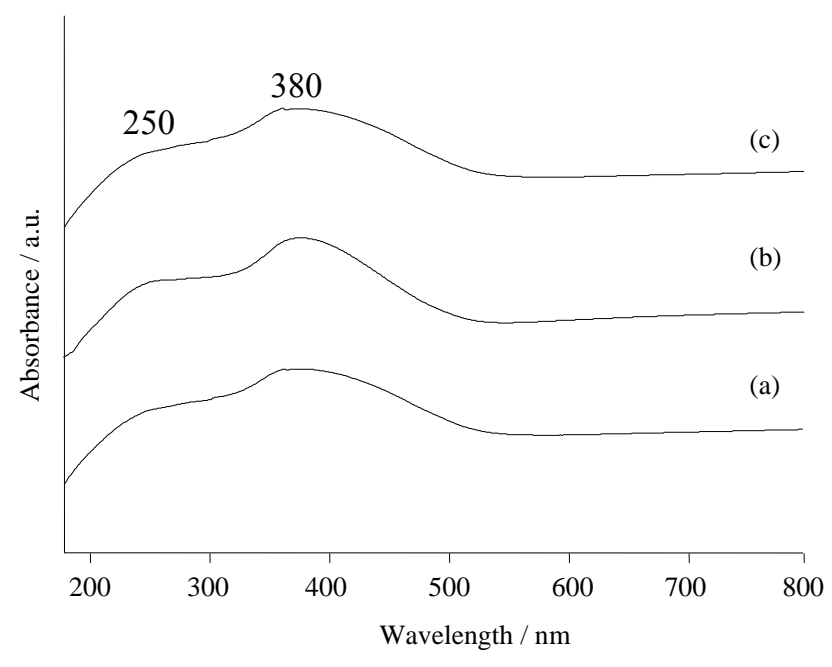

Figure.2 UV-Vis spectra of (a) $\mathrm{V} / \mathrm{HS}-\mathrm{SiO}_{2}$, (b) $\mathrm{HS} / \mathrm{V} / \mathrm{SiO}_{2}$ and (c) $\mathrm{V}-\mathrm{HS} / \mathrm{SiO}_{2}$

FTIR spectra of samples show typical silicate absorptions at 466 and $1100 \mathrm{~cm}^{-1}$ which were attributed to $\mathrm{Si}-\mathrm{O}-\mathrm{Si}$ bending and stretching vibrations, respectively [10, 11] (Fig. 3). The band at $799 \mathrm{~cm}^{-1}$ was associated with absorptions of $\mathrm{Si}-\mathrm{O}-\mathrm{V}$, which also correspond to transition metal bonding. Obviously, the sample V/HS$\mathrm{SiO}_{2}$ has the least $\mathrm{Si}-\mathrm{O}-\mathrm{V}$ bondings. It is believed that the direct sulfuric acid treatment had brought to significant alteration on the surface of silica, resulting in limited formation of $\mathrm{Si}-\mathrm{O}-\mathrm{V}$ bondings. On the other hand, $\mathrm{OH}$ group bands were observed at 1650 and $3400 \mathrm{~cm}^{-1}$. Besides, no band matching to $\mathrm{H}_{2} \mathrm{SO}_{4}$ was identified. This may be due to its low concentration used in the impregnation process and low vibration intensity of $\mathrm{SO}_{4}{ }^{2-}$ itself.

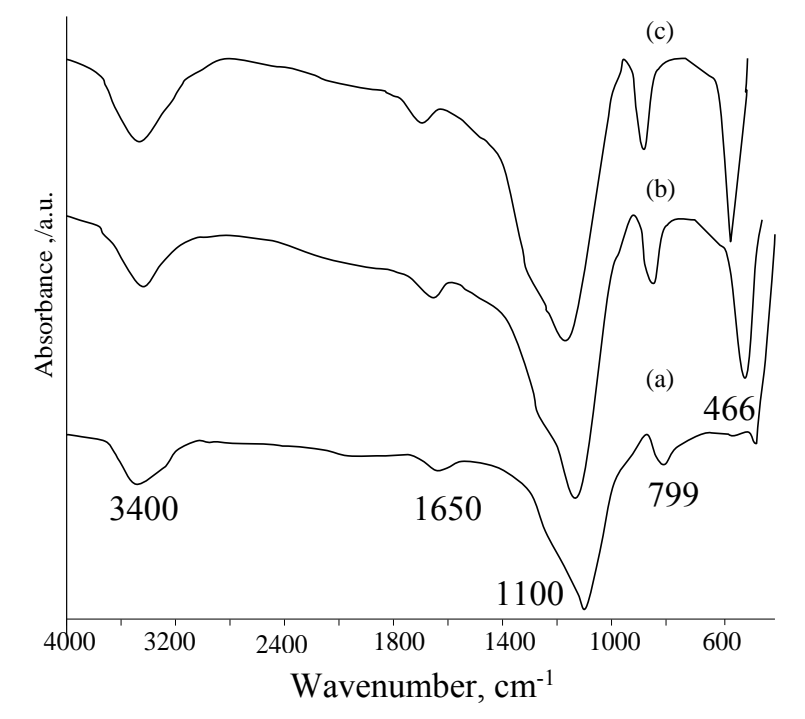

Figure.3 FTIR spectra of (a) V/HS-SiO $\mathrm{V}-\mathrm{HS} / \mathrm{SiO}_{2}$

\subsection{Catalytic Testing}

The catalytic properties of all the samples were studied in the epoxidation of 1-octene using $\mathrm{H}_{2} \mathrm{O}_{2}$ as oxidant in acetonitrile as solvent at $343 \mathrm{~K}$. After loading of $\mathrm{V}$ and sulphuric acid, the samples has remarkably enhanced catalytic activity in oxidation reaction to form 1,2epoxyoctane. As shown in Table 2, the sample $\mathrm{HS} / \mathrm{V} / \mathrm{SiO}_{2}$ had the highest yield of 1,2-epoxyoctane $(626 \pm 0.2 \mathrm{mmol})$, followed by sample V/HS-SiO $2(24 \pm 0.4 \mathrm{mmol})$. Since the $\mathrm{V}$ species is widely recognized as the active site for epoxidation reaction [11], the excellent oxidative catalytic activity of these samples could be closely associated to the existence of this $\mathrm{V}$ species in these samples as evidenced in UV-Vis DRS results.

Table.2 Yield of the product of the samples

\begin{tabular}{lc}
\hline Sample & $\begin{array}{c}\text { Yield of product }(\mathrm{mmol}) \\
\text { 1,2-epoxyoctane }\end{array}$ \\
\hline $\mathrm{SiO}_{2}$ & 0 \\
$\mathrm{~V} / \mathrm{HS}-\mathrm{SiO}_{2}$ & $24 \pm 0.4$ \\
$\mathrm{HS} / \mathrm{V} / \mathrm{SiO}_{2}$ & $626 \pm 0.2$ \\
$\mathrm{~V}-\mathrm{HS} / \mathrm{SiO}_{2}$ & 0 \\
\hline
\end{tabular}

As compare to $\mathrm{V}_{2} \mathrm{O}_{5}$ impregnated onto $\mathrm{SiO}_{2}-\mathrm{TiO}_{2}$ [5], epoxide yield of the sample $\mathrm{HS} / \mathrm{V} / \mathrm{SiO}_{2}$ was 13 time higher than that of $\mathrm{V}_{2} \mathrm{O}_{5}$ impregnated onto $\mathrm{SiO}_{2}-\mathrm{TiO}_{2}$. It may be attributed to presence of sulfuric acid which has strengthened the oxidative activity of the sample. Whereas sample $\mathrm{V}-\mathrm{HS} / \mathrm{SiO}_{2}$ has no detected yield of 1,2epoxyoctane due to different approach in synthesis procedure resulting in insufficient of oxidative sites.

It is known that 1,2-epoxyoctane will be further converted to 1,2-octanediol if Brönsted acidity is available in the samples (Fig. 4). It was reported that the direct interaction between $\mathrm{PO}_{4}{ }^{3-}$ and $\mathrm{V}_{2} \mathrm{O}_{5}$ or $\mathrm{PO}_{4}{ }^{3-}$ and $\mathrm{Nb}_{2} \mathrm{O}_{5}$ contributed to formation of Brönsted acidity $[5,12]$. However, our current research showed that there was no detection of any 1,2-octanediol after $24 \mathrm{~h}$ of reaction in all samples, strongly suggesting absence of Brönsted acid sites in the samples for the transformation of diol. Therefore, it is believed that, $\mathrm{V}^{5+}=0$ at surface might have performed as oxidative sites in the reaction, without involving in generation of Brönsted acid sites. This phenomenon implied that co-existence of sulphate group and $\mathrm{V}_{2} \mathrm{O}_{5}$ does not produce Brönsted acidity. It is noteworthy that a relatively economical support of $\mathrm{SiO}_{2}$ was used to produce an oxidative catalyst in this work. 


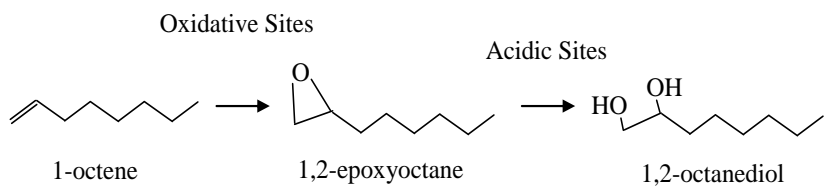

Figure.4 Reaction scheme showing the transformation between 1octene, 1,2-epoxyoctane and 1,2-octanediol.

\section{CONCLUSION}

Oxidative catalyst of sulphate-vanadia impregnated fume silica was synthesized by simple wet impregnation method. The catalytic testing results showed that $\mathrm{HS} / \mathrm{V} / \mathrm{SiO}_{2}$ was an excellent oxidative catalyst in the epoxidation of 1-octene to 1,2-epoxyoctane. This sample showed high yield of 1,2-epoxyoctane $(626 \pm 0.2 \mathrm{mmol})$ after $24 \mathrm{~h}$ reaction. Synthesis method of impregnation of V into $\mathrm{SiO}_{2}$, followed by sulphuric acid has led to the formation of more oxidative sites in the sample, resulting in better performance of catalytic activity compared to the others. It had been demonstrated $\mathrm{V}^{5+}$ played important roles as oxidative sites for 1-octene epoxidation and fumed silica served as a potential support for oxidative catalyst.

\section{ACKNOWLEDGEMENTS}

The authors acknowledge funding from the Ministry of Higher Education (MOHE) and Universiti Teknologi Malaysia for the Research University Grant and PSAN Grant (Vote no: Q.J130000.2609.10J66).

\section{REFERENCES}

(1) J. Bu, S. Yun, H. Rhee. 2000. Korean. J. Chem. Eng. 17(1): 76-80.

(2) C.Gannoun, A.Turki, H.Kochkar, RDelaigle, P. Eloy, A Ghorbel, E.M.Gaigneaux, 2014. Appl. Catal. B Environ. 147, 58-64.

(3) M. Palacio, P.I.Villabrille, G.P.Romanelli, P.G.Vázquez, C.V. Cáceres, , 2012. Appl.Catal. A Gen. 147-148, 273-280.

(4) D.P. Serrano, M.A Uguina, G. Ovejero , R.Van Grieken, M. Camacho, 1995. Microporous. Mater. 4, 273-282.

(5) S. L. Lee, H. Nur, H. Hamdan. 2009. Catal. Lett. 132: 28-33.

(6) S.L. Lee, H. Nur, P.W. Koh, J.M. Ekhsan, S. C. Wei. 2011. Int. J. Appl. Phys. Math. 1: 43-47.

(7) S.L. Lee, S.C. Wei, H. Nur, H. Hamdan. 2010. Int. J Chem React Eng. Vol 8, Article 63.

(8) S. Shylesh, S.P. Mirajkar, A.P. Singh. 2005.J. Mol. Catal. A: Chem. 234: $57-63$.

(9) L. S. Ling, H. Hamdan. 2008.J. Non-Cryst. Solids. 354: 3939-3943.

(10) M.C. Capel-Sanchez, J.M. Campos-Martin, J.L. G. Fierro. 2003. Appl. Catal A: Gen. 246: 69-77.

(11) M. Tanaka, H. Shima, T. Yokoi, T. Tatsumi, J. N. Kondo. 2011. Catal. Lett.141: 283-292.

(12) J. Mohd Ekhsan, S. L. Lee, H. Nur. 2014. Appl. Catal A: Gen.471: 142-148. 